\title{
Knowledge level of milk and meat cattle breeders in Qena governorate, Egypt
}

\author{
Murad E. H. E. T., Hassan O. D., Nagi A. A." \\ Department of Agricultural Extension and Rural Sociology, Faculty of Agriculture, Al-Azhar University, Assuit, Egypt
}

\begin{abstract}
This research aimed at determining the Knowledge level of the researched breeders with regard to the indicative technical recommendations related to the operations of raising, feeding and caring for milk and meat cattle, and determining the relationship between the Knowledge level of the researched breeders and the independent variables studied, and identifying the problems facing the breeders researched in the breeding, feeding and care of milk and meat cattle from their point of view. The research was conducted on a sample of breeders who have livestock in Qena Governorate, which has a strength of 370 educators, and they were randomly chosen through the selection of the two largest centers in the governorate in terms of the number of breeders with livestock, namely the Dishna and Abu Tisht centers, and then the largest village was chosen from each of the centers mentioned in terms of the number of breeders who have livestock, as the village of Al-Samta was chosen as a marine for the Dishna Center, and the number of respondents was 269 educators and the village of Bahri Samhoud from the Abu Tisht Center has reached the number of respondents by 101 educators. Data were collected from the respondents through a personal interview using a questionnaire. The data was used to display and analyze the frequencies and percentages, weighted average arithmetic, proportional conformity test (Ka2), and the coefficient of coefficient, and the data was processed and analyzed using the Statistical Package for Social Sciences (SPSS). The research reached many results, the most important of which are:

- More than half of the respondents (51.6\%) had a total Knowledge level with recommendations for raising, feeding, and caring for milk and meat cattle was low, while more than a third of the respondents were $36.5 \%$, their cognitive level was average with those recommendations, while $11.9 \%$ of the respondents, their level of knowledge was high with those recommendations.

- There is a moral relationship between their overall Knowledge level with the recommendations of raising, feeding and caring for milk and meat cattle, and between the educational level, the number of years of experience in livestock raising, information sources, and the trend towards agricultural extension.

- $\quad$ The most important problems facing breeders researched in the breeding, feeding and care of milk and meat cattle are: the high price of feed and the lack of government support, the weak extension services provided, the small number of veterinarians, and the weak veterinary services provided.
\end{abstract}

Keywords: knowledge level, milk and meat cattle, Qena governorate.

* Corresponding author: Nagi A. A, 


\section{المستوى المعرفي لمربي ماثية اللبن واللحم بمحافظة قنا بجمهورية مصر العربية}

السيد حسين السيد طلعت مر اد ، أسامة دسوقي حسن عفيفي ، أحمد عبد الماللك ناجى محمد

$$
\text { قسم الإرشاد الزراعي و المجتمع الريفي ، كلية الزراعة ، جامعة الأزهر - فرع أسيوط ، جمهورية مصر العربية }
$$

استهدف هذا البحث تحديد المستوى المعرفى للمربين المبحوثين فيما يتعلق بالتوصيات الفنية الإرشادية الخاصة بعمليات تربية

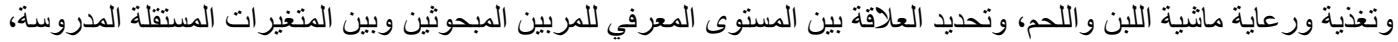

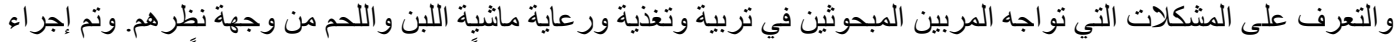

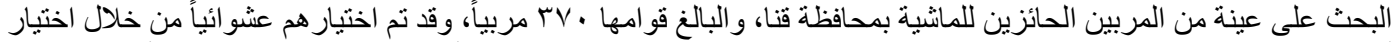

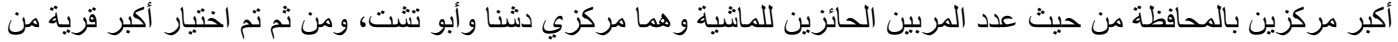

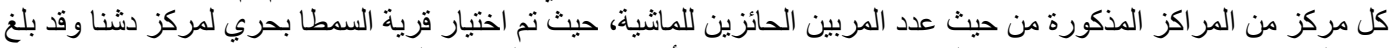

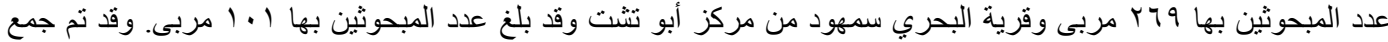

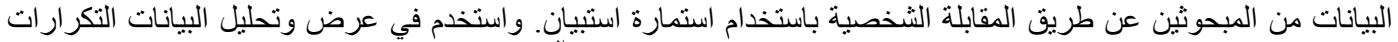

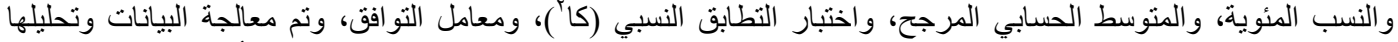

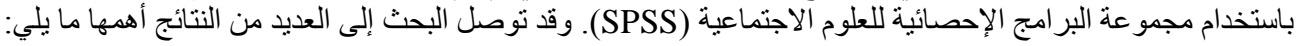

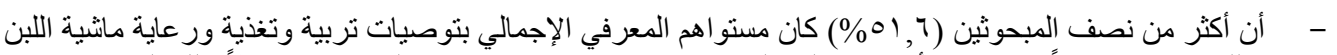

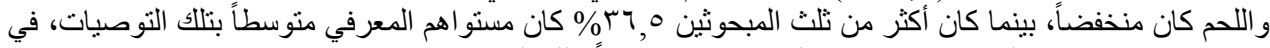

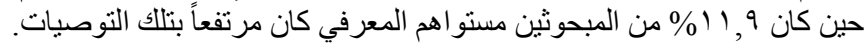

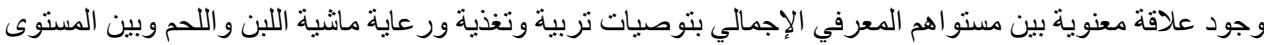

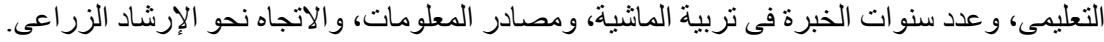

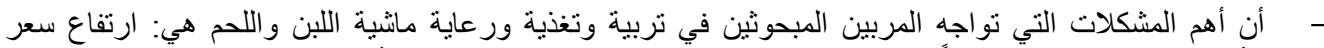

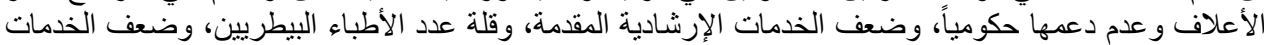

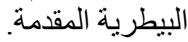

كلمات دالة: مستوى معرفي، ماثية اللبن و اللحم، محافظة قنا. 


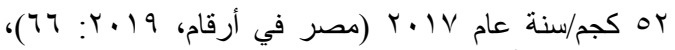

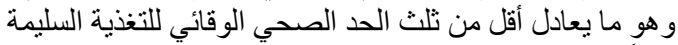

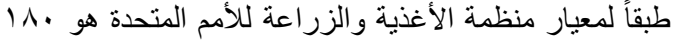

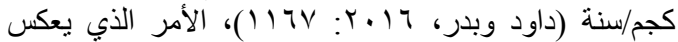

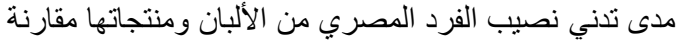

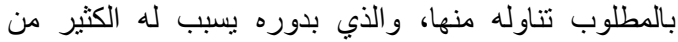

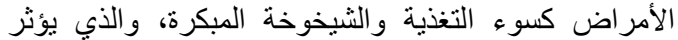

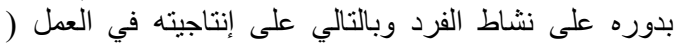

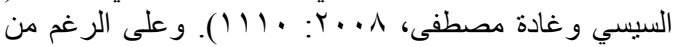

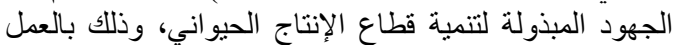

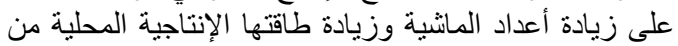

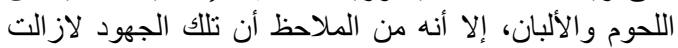

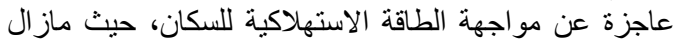

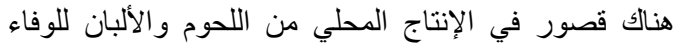

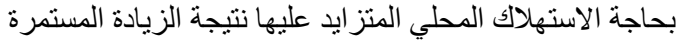

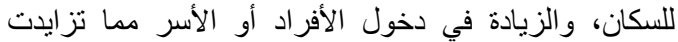

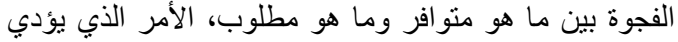

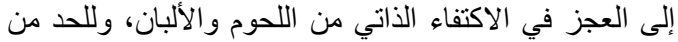

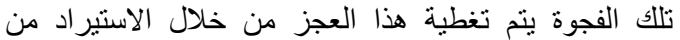

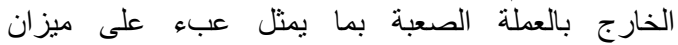
المدفوعات، وتمثل كمية الألبان ومنتجاتها التي تم استير التيل ادها

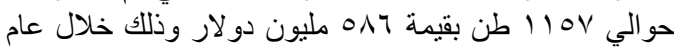

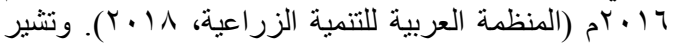

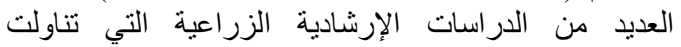

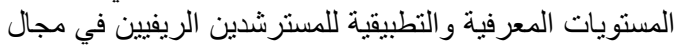

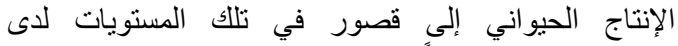

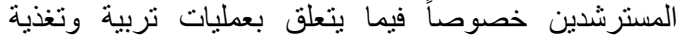
ور عاية الحيو انات المزرعية، وأشارت كذللك إلى وجود الكين الكثير

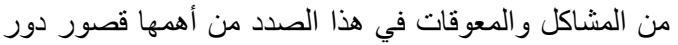

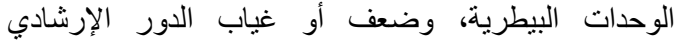

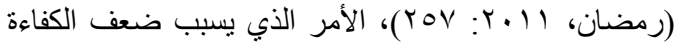

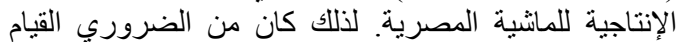

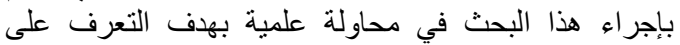

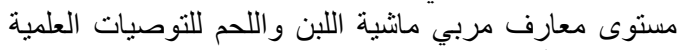
في إنتاج الألبان واللحوم، لتحديد النقص الفعلي في معارفهر بهذه التوصيات.

\section{أهمية البحث}

يمكن الاستفادة من نتائج هذا البحث في وضع مؤشر ات حقيقات البرتية

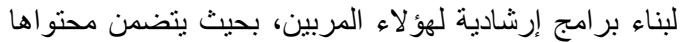

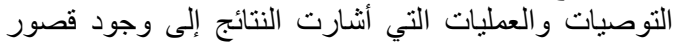

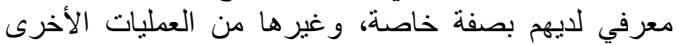

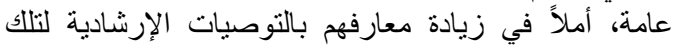

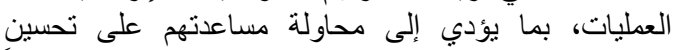
وتطوير قدراتهم الإنتاجية وإنتاج منتج نظيف وآمن صحياً
مقدمة البحث ومشكلته

يعد قطاع الإنتاج الحيو اني قطاعاً رئيسياً و هاماً في دعم الإنتاج

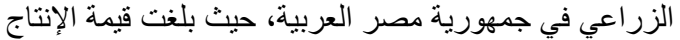

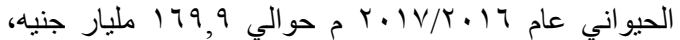

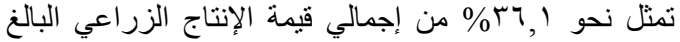

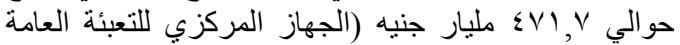

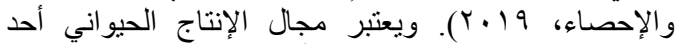

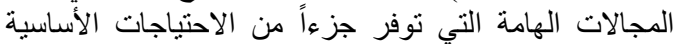

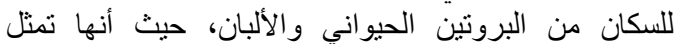

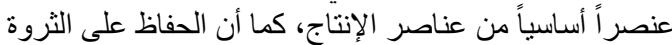

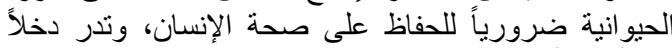

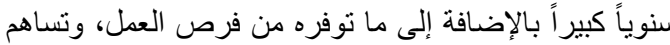

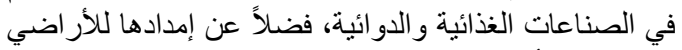

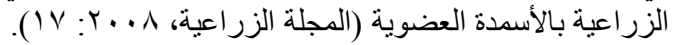

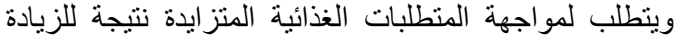

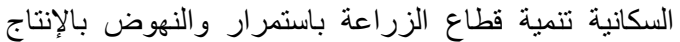

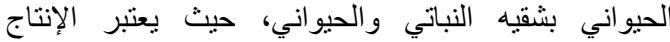

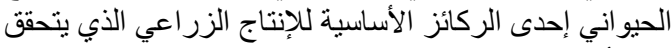

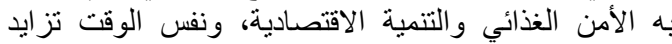

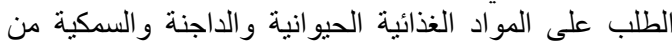

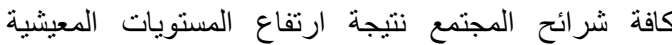

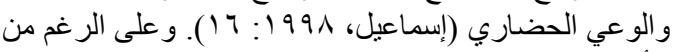

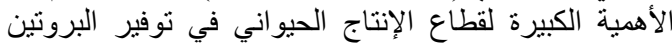

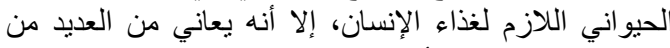

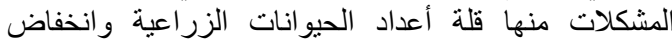

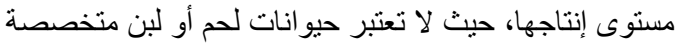

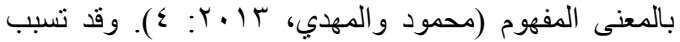

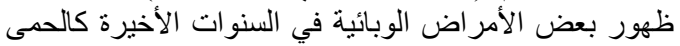

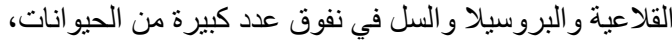

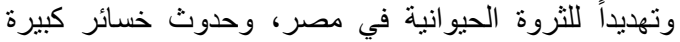

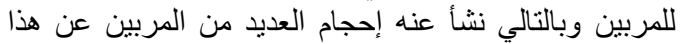

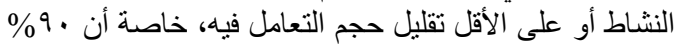

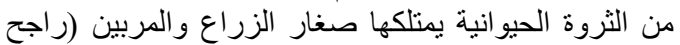

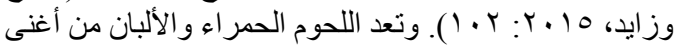

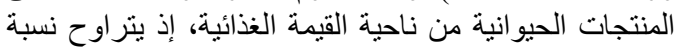

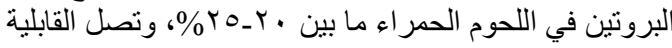

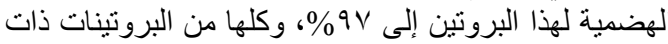
القيمة الغذائية العالية لاحتو ائها على الأحماض الألى الأمينية اللازمة الئنة

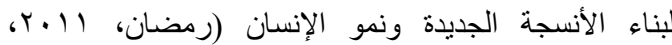
عالية (YOV عالية القيمة الغذائية بالمقارنة بالئن بالمصادر الأخرى للإنتاج

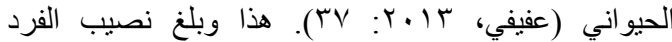

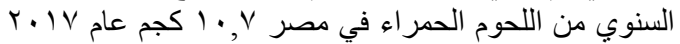

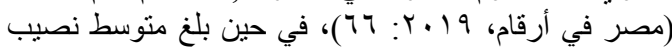

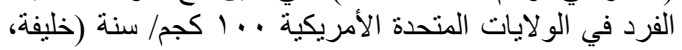

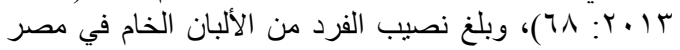


من

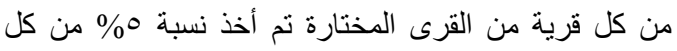

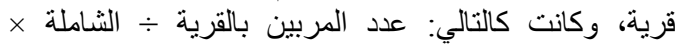

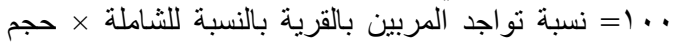

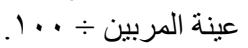

جدول (1): قرى العينة المختارة من كل مركز ونسبة تمثيلها في العينة.

\begin{tabular}{|c|c|c|c|c|}
\hline 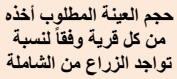 & النسبة المنوية & عدالقرى المربين & القرية & المركز \\
\hline$r 99$ & $\%$ \%r, & $\theta, r{ }^{\circ}$ & السمطا بحري & |دشنا \\
\hline 1.1 & $\%^{\mathrm{rV},{ }^{r}}$ & $r, 10$ & البحري سمهود & أبو تُثت \\
\hline rv. & $\% 1 \ldots$ & $\mathrm{v}, \xi \cdots$ & $r$ & |المجمــوع \\
\hline
\end{tabular}

المصدر: مديرية الزراعة بقنا

جمع البيانات: تم جمع بيانات البحث من المربين المبحوثين

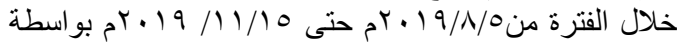
استمارة الاستبيان بالمقابلة الثخصية. أدوات التحليل الإحصائي: هذا وقدانئ استخدمت التكرارات

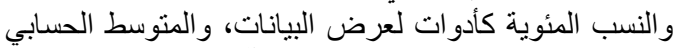

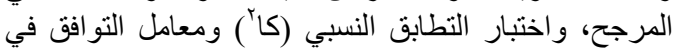

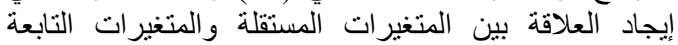

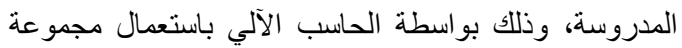
البرامج الإحصائية للعلوم الاجتماعية (SPSS).

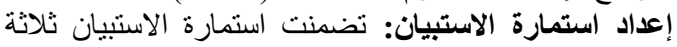

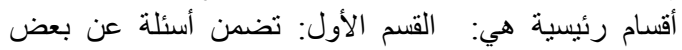

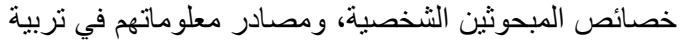
وتغذية ورعاية ماثية اللبن واللحم، واتجاهين النهاتهم نحو الإرشاد

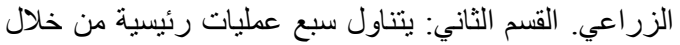

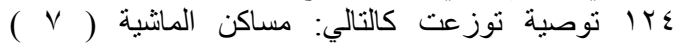

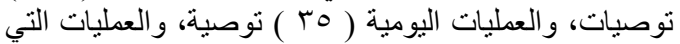

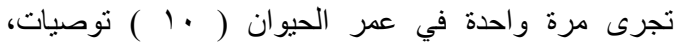

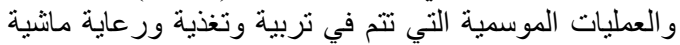

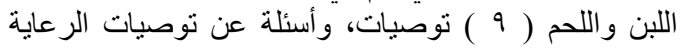

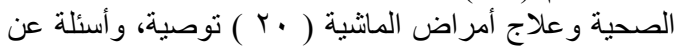

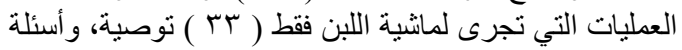

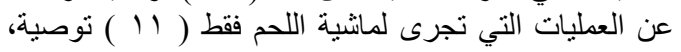

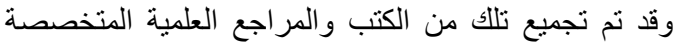

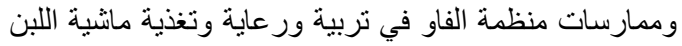

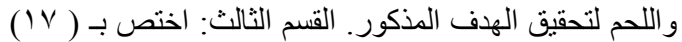
مشكلة تواجه المربين المبحوثين في تربية وتغذية وركاية الثناية

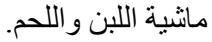

\section{المعالجة الكمية للبيانات}

أ. المتغيرات المستقلة المدروسة وهي:

1ـ السن: وتم قياسه بعدد سنوات عمر المبحوث لأقرب سنة
للمستهلك، و إلىى زيادة دخل المربين وتحسين أحوالهم الاقتصادية والاجتماعية.

\section{أهداف البحث}

1- التعرف على الخصائص الثخصية والاجتماعية والاقتصادية للمبحوثين.

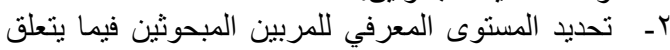
بالتوصيات الفنية الإرشادية الخاصنة بعمليدات تربية وتغذية ور عاية ماشية اللبن و اللحم. لكاتية

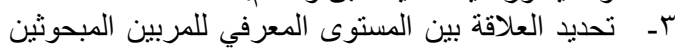

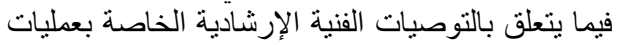

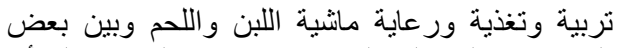

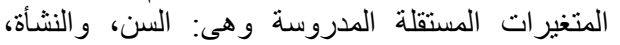

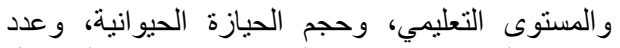

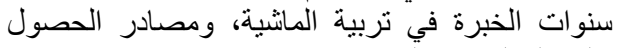

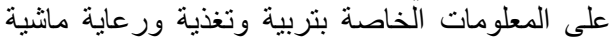

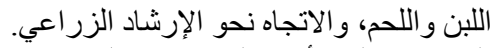

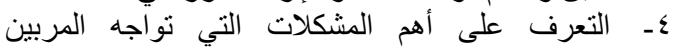
المبحوثين في تربية وتغذية ور عاية مانشية اللبن واللحم

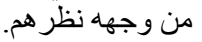

\section{فروض البحث}

لتحقيق هدف البحث الثالث تم صياغة الفرض البحثي التالي:

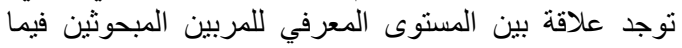

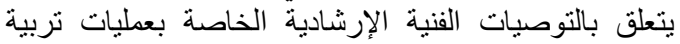

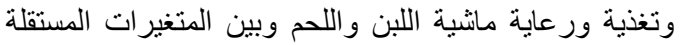

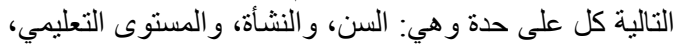

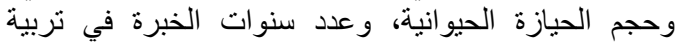

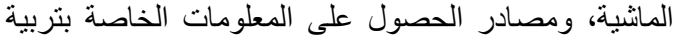

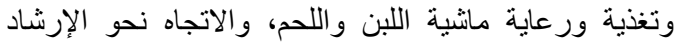

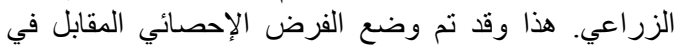
صورته الصفرية لاختبار صحة الفرض البحضي.

\section{الطريقة البحثية}

منطقة البحث: نم إجراء هذا البحث على البه المربين للماثية

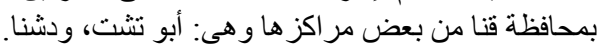

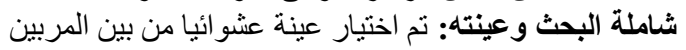

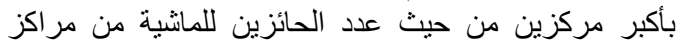

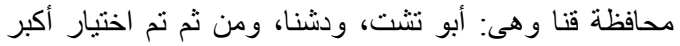

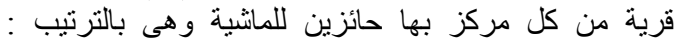

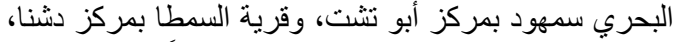

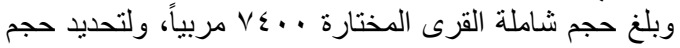

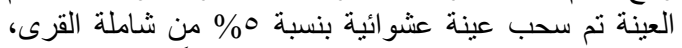

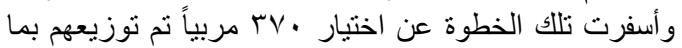

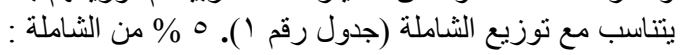




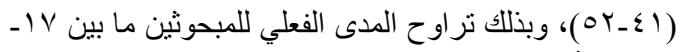
( ) ب. ب. المتغير التابع

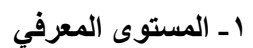

تم قياسه بسؤال المربين المبحوثين عن معرفتهم بتوصيات

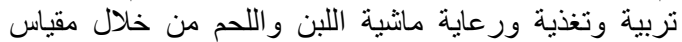

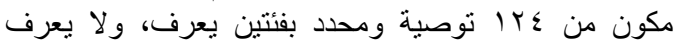

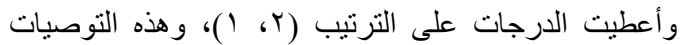
موز عة على V عمليات على النحو التالي:

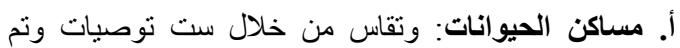

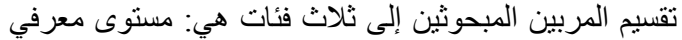

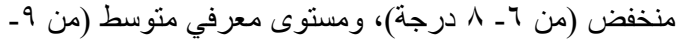

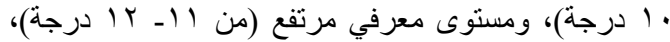

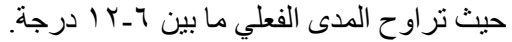

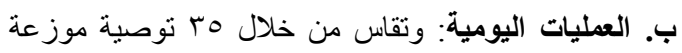

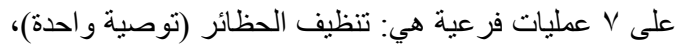

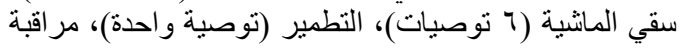

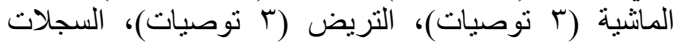

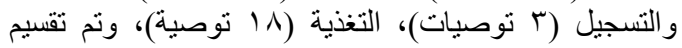

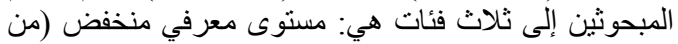

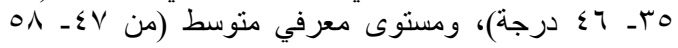

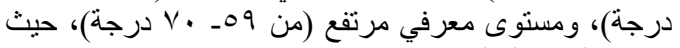

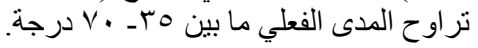

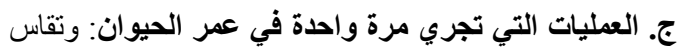

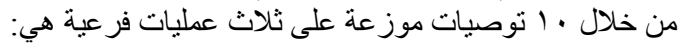

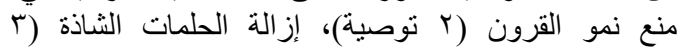

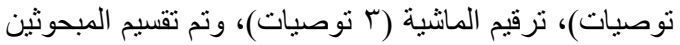

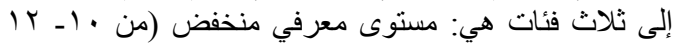

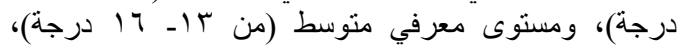

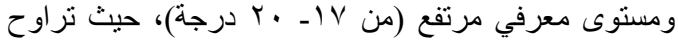
المدى الفعلي ما بين • • إـ • ب درجة.

د. العمليات الموسمية التي تتم في تربية وتغنية ورية ورعاية

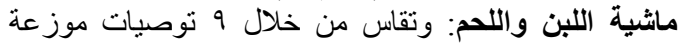

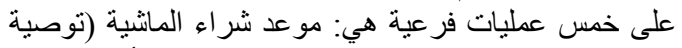

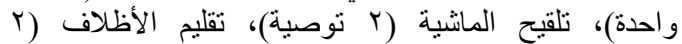

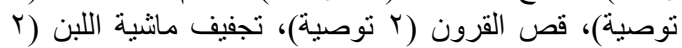

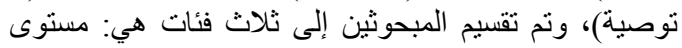

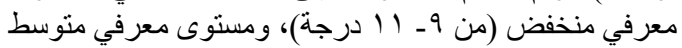

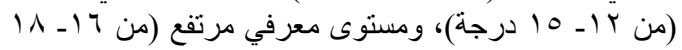

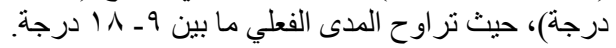

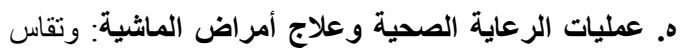

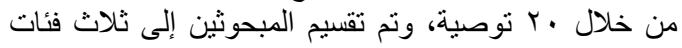

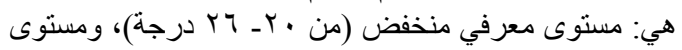

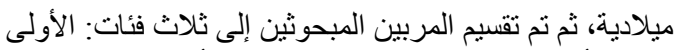

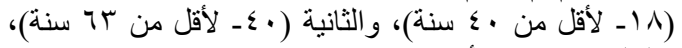
و الثالثة (rآ سنة فأكثر).

r- النشأة: وتم تقسيم المبحوثين وفقاً للنشأة إلى: ريفي (r) (؟)، حضري (1) (1)

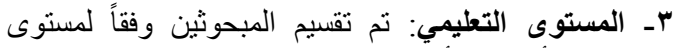

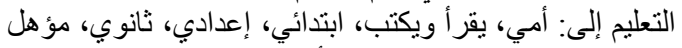

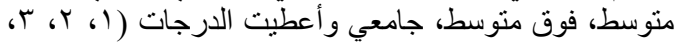

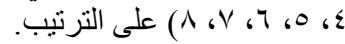

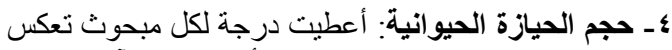
حجم حيازته للحيو انات المزر الئة اعطية وفقأ للمقياس الآتي: جمال

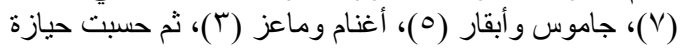

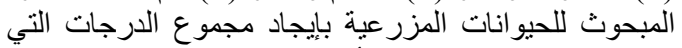

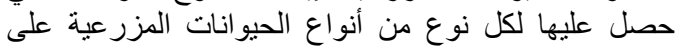

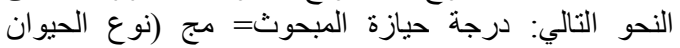
المزرعي × عدد الحيو انات من كل نوع المبحة.

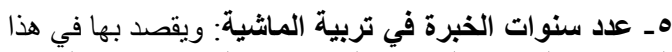

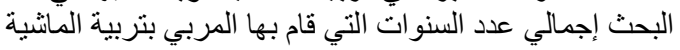

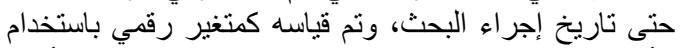

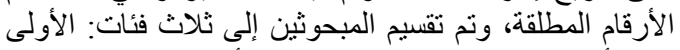

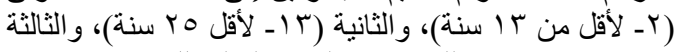

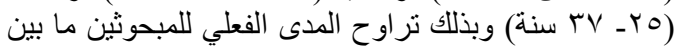

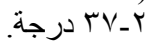

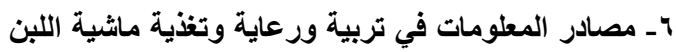

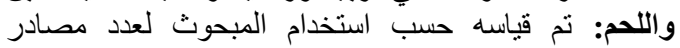

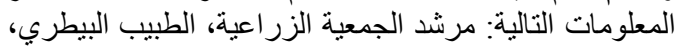

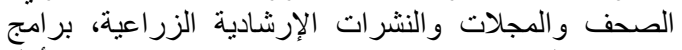

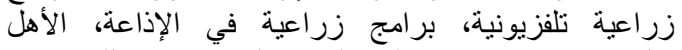

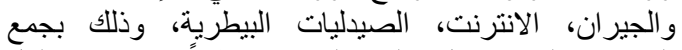

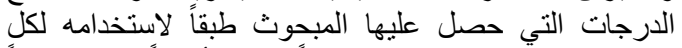

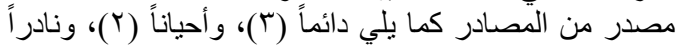

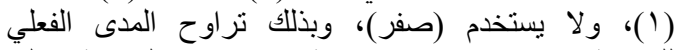

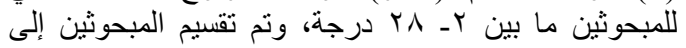

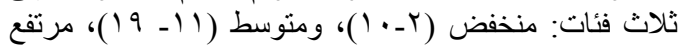

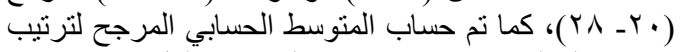
مصادر المعلومات حسب استخدام المبحوثين لكل مصدر.

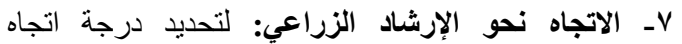

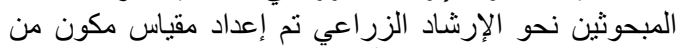

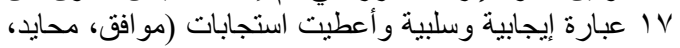

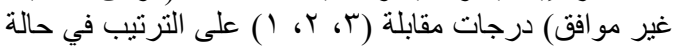

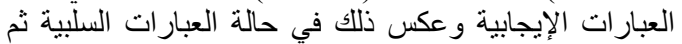

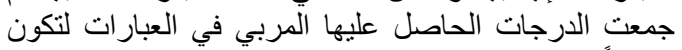

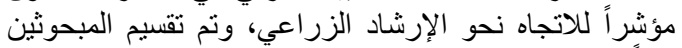

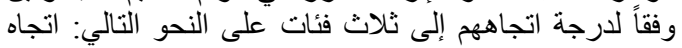

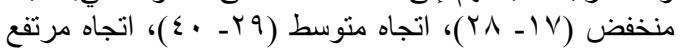




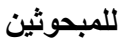

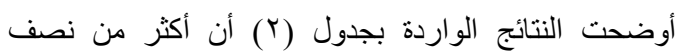

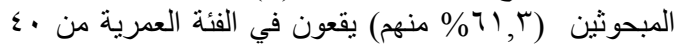

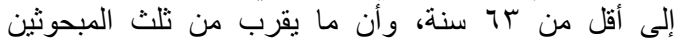

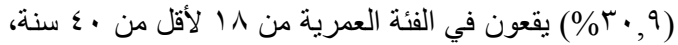

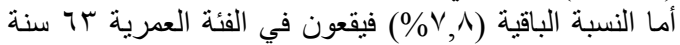
فأكثر. وأن الغاليية العظمى للمربين المبحوثين (90,9\%

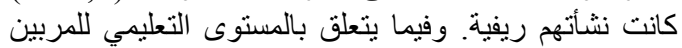

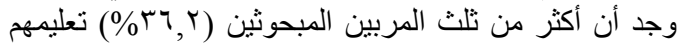

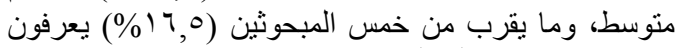

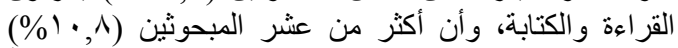
أميين، وقد تلقى أقل من عشر المبن المبحوثين

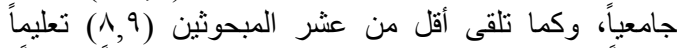

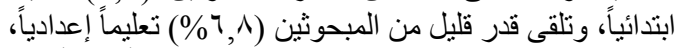

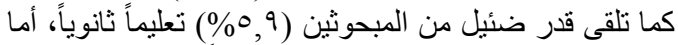

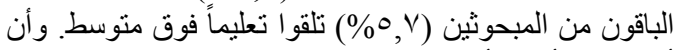

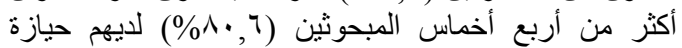

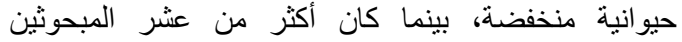

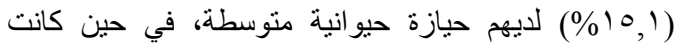

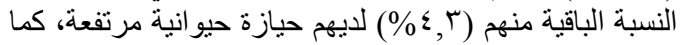

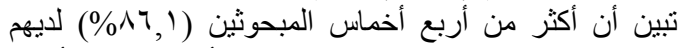

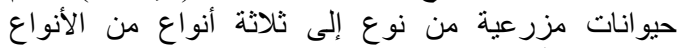

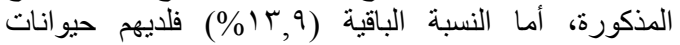

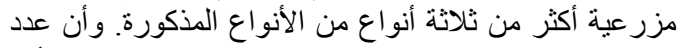

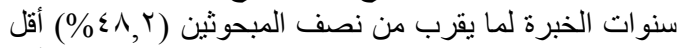

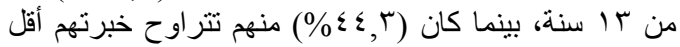

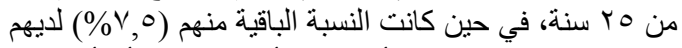

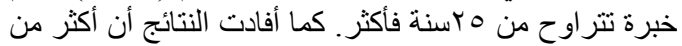

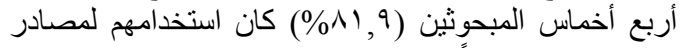

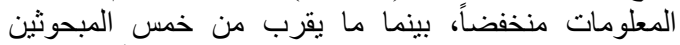

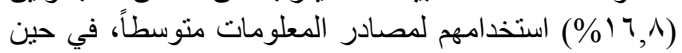

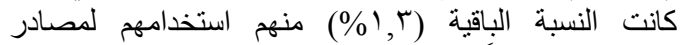

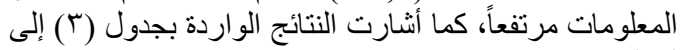

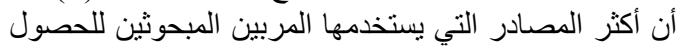

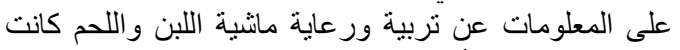

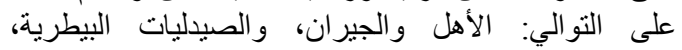

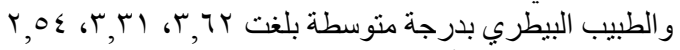

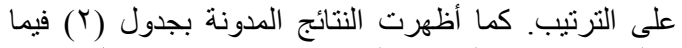

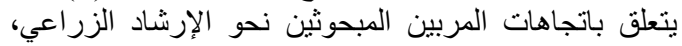

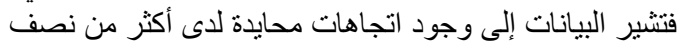

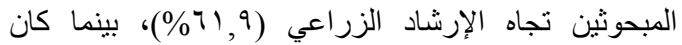

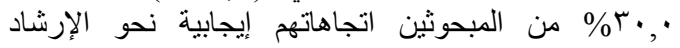

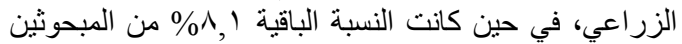
اتجاهاتهم سلبية نحو الإرشاد الزراعي.

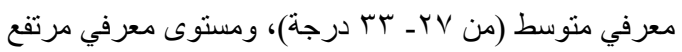

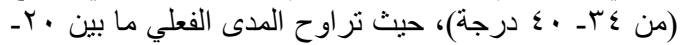

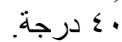

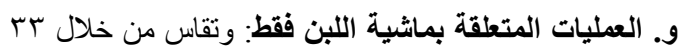

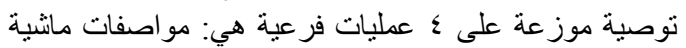

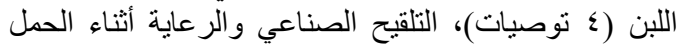

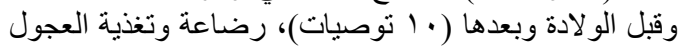

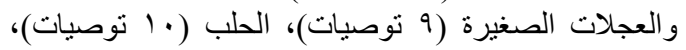

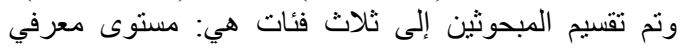

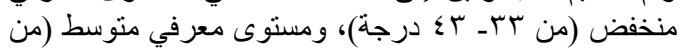

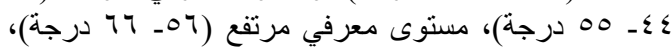

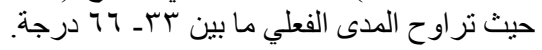

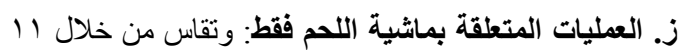

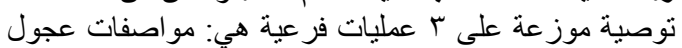

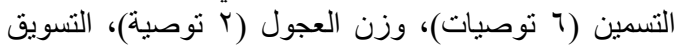

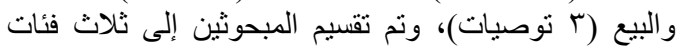

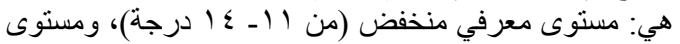

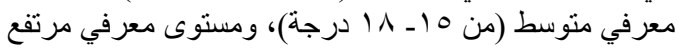

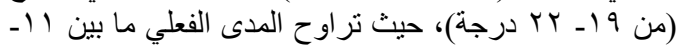

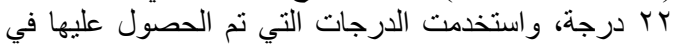

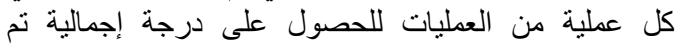

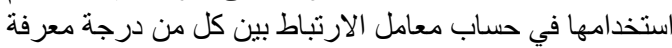

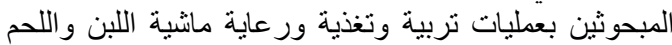

$$
\text { و المتغير ات المدروسة. }
$$

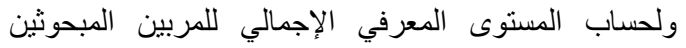

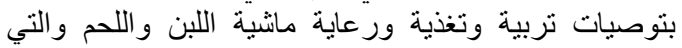

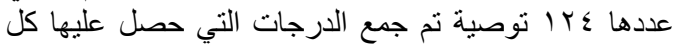

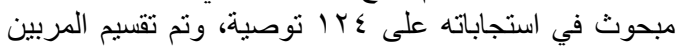

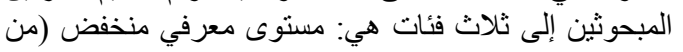

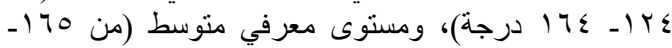

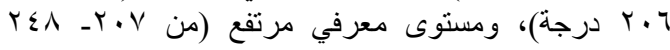

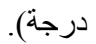

r- المشكلات التي تواجه المبحوثين في تربية وتغذية ورعاية ماثبية اللبن

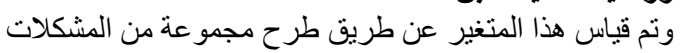

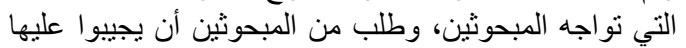

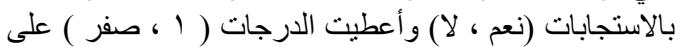
الترتيب.

\section{النتائج ومناقشتها}

أولا: الخصائص الثخصية والاجتماعية والاقتصادية 


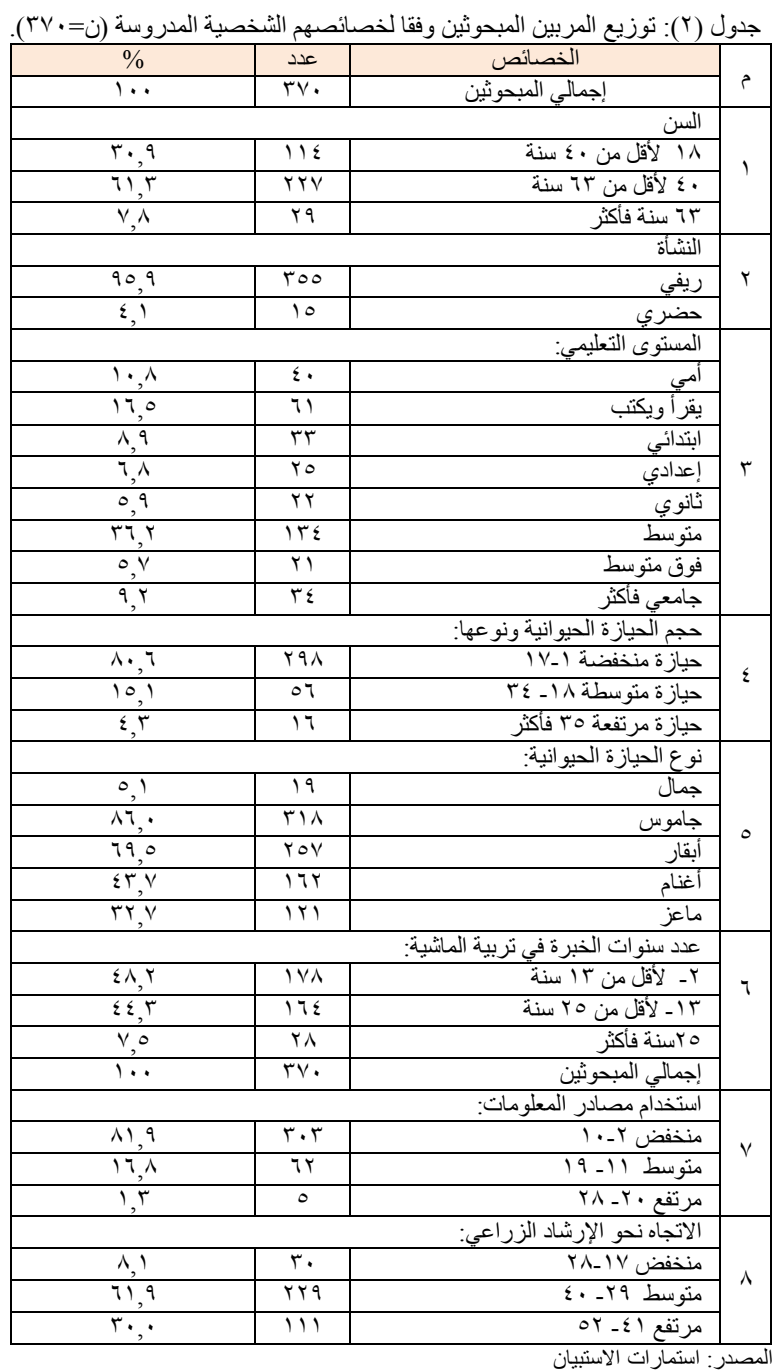

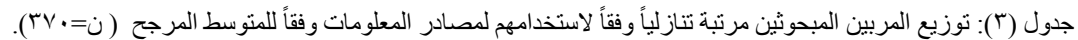

\begin{tabular}{|c|c|c|c|c|c|c|c|c|c|c|c|}
\hline \multirow{3}{*}{ الترتيب } & \multirow{3}{*}{ المرجح } & \multicolumn{8}{|c|}{ الاستخدام } & \multirow{3}{*}{ المصادر } & \multirow{3}{*}{ s } \\
\hline & & \multicolumn{2}{|c|}{$\gamma$} & \multicolumn{2}{|c|}{ نادر ا } & \multicolumn{2}{|c|}{ أحيانا } & \multicolumn{2}{|c|}{ دائما } & & \\
\hline & & $\%$ & عدد & $\%$ & عدد & $\%$ & عدد & $\%$ & عدد & & \\
\hline 7 & $1, r v$ & $V 7, r$ & TAY & 11,7 & $\varepsilon r$ & 11,1 & 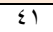 & 1,1 & $\varepsilon$ & مرشد الجمعية أو المهندس & $T$ \\
\hline$r$ & $r, 0 \leqslant$ & ri, 9 & 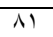 & 10,9 & 09 & $\varepsilon \wedge, 9$ & 111 & $\frac{1}{1 T, r}$ & $\varepsilon 9$ & الطبيب البيطري & r \\
\hline V & $1, Y \varepsilon$ & AV, & TYY & $\varepsilon, 1$ & 10 & $v_{,} \cdot$ & $r 7$ & 1,9 & $\mathrm{~V}$ & الصحف و المجلات و النشر ات & $r$ \\
\hline 0 & $1, \varepsilon r$ & $V V, 7$ & TAV & 0,1 & 19 & $1 \leqslant, 1$ & or & $r, r$ & Tr & بر امج زر اعبة تللفزيونية & $\varepsilon$ \\
\hline ل V Vكرر & $1, r \leq$ & 10,1 & 10 & $v_{,} \cdot$ & YY & 7,1 & ro & 1,1 & $\varepsilon$ & بر امج زر اعية إذاعبة & 0 \\
\hline 1 & $r, 7 r$ & $7, r$ & $r^{T}$ & $r, r$ & $\Lambda$ & $10, \varepsilon$ & ov & $V 7, Y$ & TAY & الأهل و الجيران & 7 \\
\hline$\varepsilon$ & 1,70 & 79,0 & rOV & 7,1 & To & TY,V & $\varepsilon V$ & $11, \cdot$ & $\varepsilon$ & الانترنت & V \\
\hline r & $r, r)$ & $11, \varepsilon$ & $\varepsilon r$ & 1,9 & V & $r, 7$ & $11 \mathrm{~V}$ & 00,1 & $r \cdot \varepsilon$ & الصيدليات البيطرية & $\wedge$ \\
\hline$\Lambda$ & $1,1 \varepsilon$ & 95,1 & $r \varepsilon$ & $r, 0$ & 14 & $r, \cdot$ & 11 & $1, \xi$ & 0 & الندو ات الإرشادية و المؤتمرات & 9 \\
\hline $1 \cdot$ & 1,11 & $9 r, r$ & $r \leqslant 0$ & $r, 0$ & $\pi$ & $r, r$ & $\wedge$ & 1,1 & $\varepsilon$ & محطة بحوث الإنتاج الحيو اني & 1. \\
\hline 9 & 1,14 & $9 \leqslant, r$ & $r \leqslant 9$ & $1, \xi$ & 0 & 1,9 & V & $r, \varepsilon$ & 9 & كلية الزراعة & 11 \\
\hline
\end{tabular}




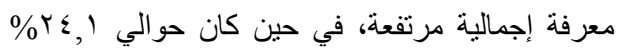

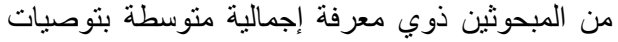
العمليات الموسمية.

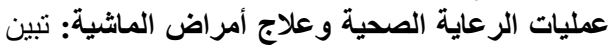

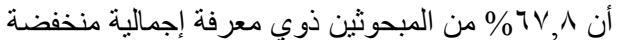

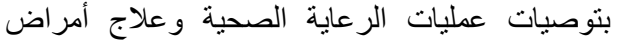

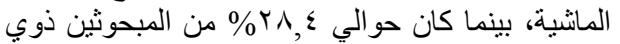

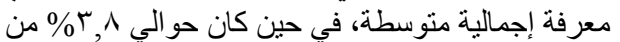

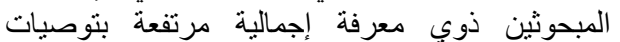
عمليات الرعاية الصحية و علاج أمر اض المبنة الماشية.

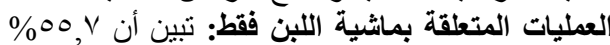

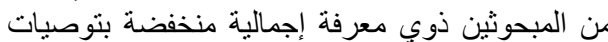

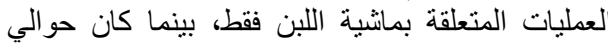

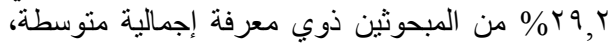

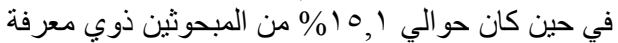
إجمالية مرتفعة بتوصيات العمليات المتعلقة بماثية اللبن دين

$$
\text { فقط. }
$$

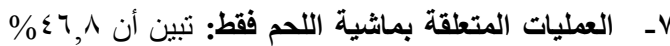

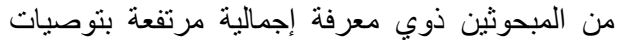

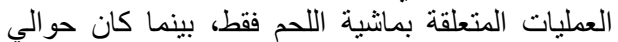

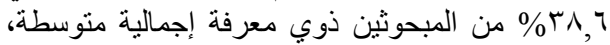

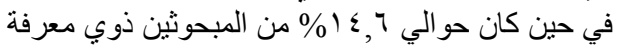
إجمالية منخفضة بتوصيات العمليات المتعلقة بمانشية اللحم فقط. A- المعرفة الإجمالية للمربين:nتبين أن مستوى المعرفي تئي

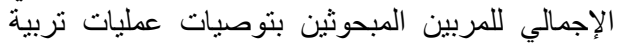

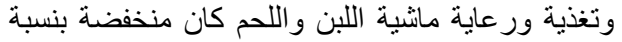

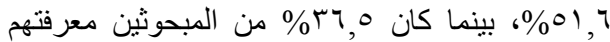

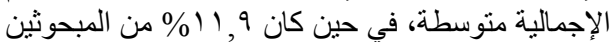

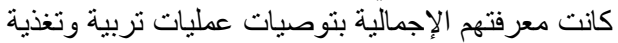
ور عاية ماثية اللبن و اللحم مرتفعة.
ثانيا: المستوى المعرفي للمربين المبحوثين فيما بتعلق بإنقائي

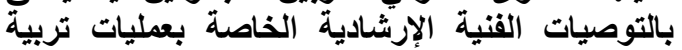
وتغذية ورعاية ماثية اللبن والتئية

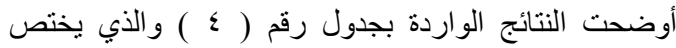

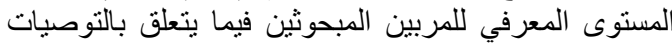

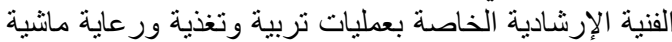
اللبن و اللحم ما يلي: - الارنية

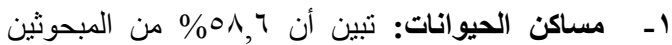

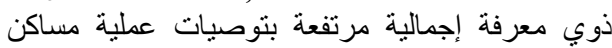

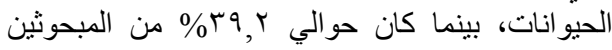

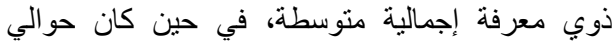

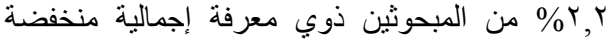

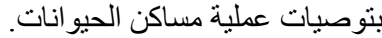

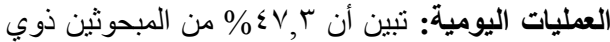

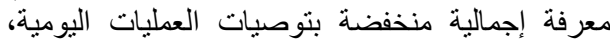

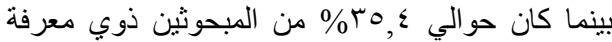

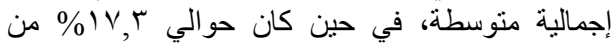

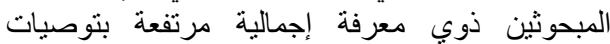

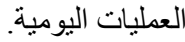

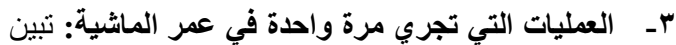

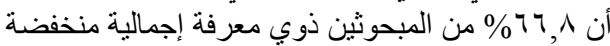

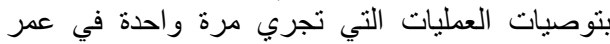

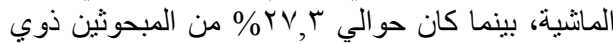

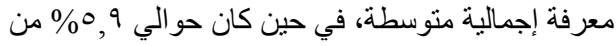

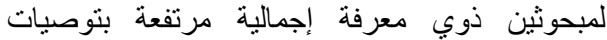
العمليات التي تجري مرة واحدة في عمر المانشية.

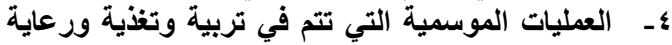

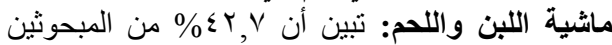

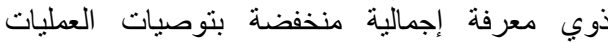

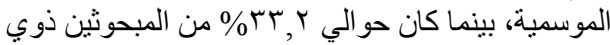

جدول (§): توزيع المربين المبحوثين وفقاً لمستو اهم المعرفي الإجمالي بعمليات تربية وتغذية ور عاية ماثنية اللبن و اللحم. (ن=• (Y).

\begin{tabular}{|c|c|c|c|c|c|c|c|}
\hline \multicolumn{6}{|c|}{ المستوى المعرفي } & \multirow{3}{*}{ 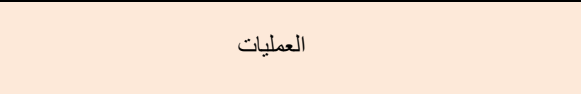 } & \multirow{3}{*}{ م } \\
\hline \multicolumn{2}{|c|}{ منخفضة } & \multicolumn{2}{|c|}{ متوسطة } & \multicolumn{2}{|c|}{ 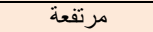 } & & \\
\hline$\%$ & عدد & $\%$ & عدد & $\%$ & عدد & & \\
\hline$T, Y$ & $\Lambda$ & $r q, r$ & $1 \leq 0$ & 01,7 & YIV & مساكن الحيو انات & $T$ \\
\hline$\varepsilon v, r$ & IVo & $r 0, \xi$ & $1 \pi$ & IV,r & $7 \varepsilon$ & العمليات اليومية & r \\
\hline 77,1 & $r \leqslant V$ & $T V, r$ & 1.1 & 0,9 & Tr & العمليات التي تجري مرة واحدة في عمر الحيوان & $r$ \\
\hline$\varepsilon r, Y$ & 101 & $r \varepsilon, 1$ & 19 & $r+, r$ & זra & العمليات الموسمية التي تتم في تربية وتغذية ور عاية ماثية اللبن و اللحم & $\varepsilon$ \\
\hline$T \mathrm{~T}, \mathrm{~A}$ & Y01 & $T \wedge, \xi$ & 1.0 & $r, \wedge$ & $1 \varepsilon$ & عمليات الرعاية الصحية و علاج أمر اض الماثية & o \\
\hline $00, \mathrm{~V}$ & $r \cdot T$ & rq,, & $1 \cdot 1$ & 10,1 & 07 & العمليات المتعلقة بمانشية اللبن فقط & 7 \\
\hline $1 \leqslant, 7$ & $0 \leqslant$ & $r \Lambda, \uparrow$ & $1 \leqslant r$ & $\sum \uparrow, \wedge$ & IVT & العمليات المتعلقة بماثية اللحم فقط & $\mathrm{V}$ \\
\hline 01,7 & 191 & 44,0 & 150 & 11,9 & $\varepsilon \varepsilon$ & إجمالي المعرفة & $\Lambda$ \\
\hline
\end{tabular}


ماشية اللبن و اللحم وبين المستوى التعليمي عند مستوى 1 •, •

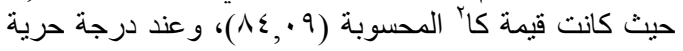

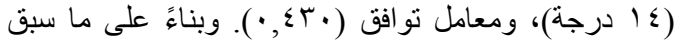

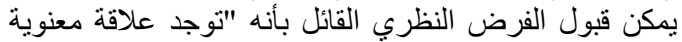

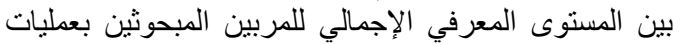

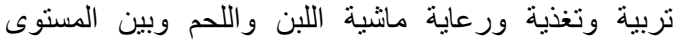

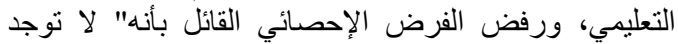

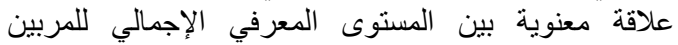
المبحوثين وبين المستوى التعليمي.

ع - عدد سنوات الخبرة في تربية الماشية: تبين وجود علاقة

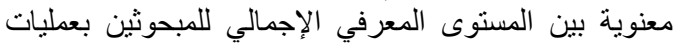

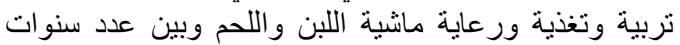

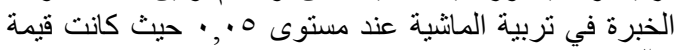

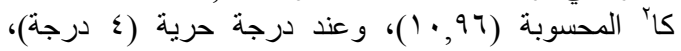

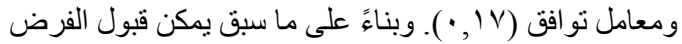
النظري القائل بأنه " توجد علاقلة وبنة معنوية بين المستوى المعرفي الإجمالي للمربين المبحوثين بعمليات تربية وتئ وتغذية ورعاية ماثية اللبن و اللحم وبين عدد سنوات الخبرة في تربية

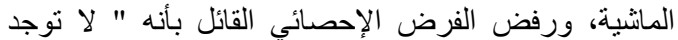
علاقة معنوية بين المستوى المعرفي للمربين المبحوثين وبين عدد سنوات الخبرة في تربية الماثية.

هـ مصادر المعلومات: تبين وجود علاقة معنوية بين المستوى

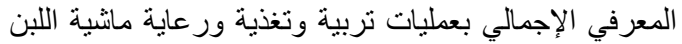

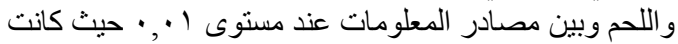

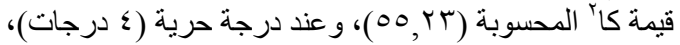

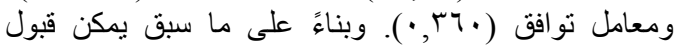

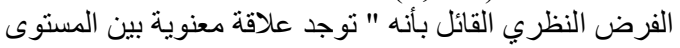

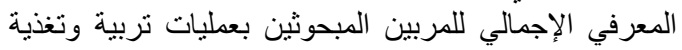

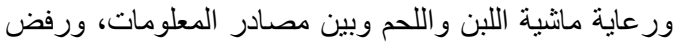
الفرض الإحصائي القائل بأنه " لا توجد مالمدين علاقة معنوية بين

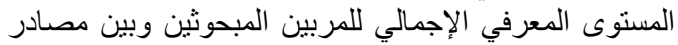
المعلومات.

7- الاتجاه نحو الإرشاد الزراعي: تبين وجود علاقة معنوية

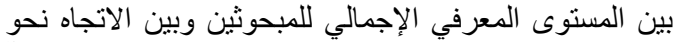

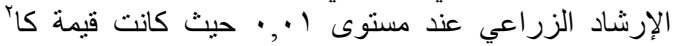

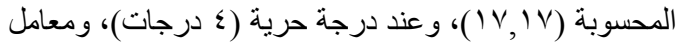

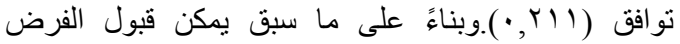

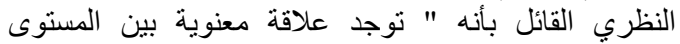

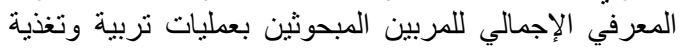

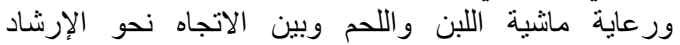

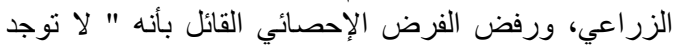

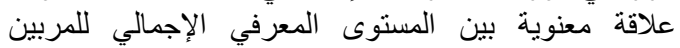

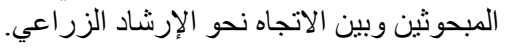

ومن العرض السابق مما يتضح أن معرفة المربين الإجمالية

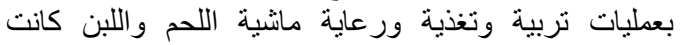
منخفضة في العمليات التالية: (العمليات اليومية، ورية، والعمليات التي تجرى مرة واحدة في عمر الماثية، و العمليات الموسمية،

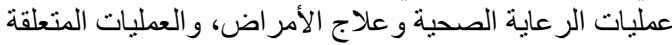
بماثية اللبن)، وذلك يتطلب من الجهاز الإرشادي والواتية الوحدات

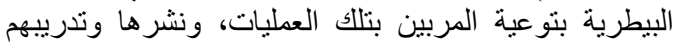

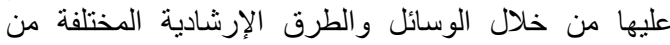

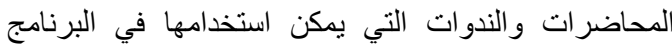

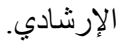

ثالثا: العلاقة بين المستوى المعرفي للمربين المبحوثين

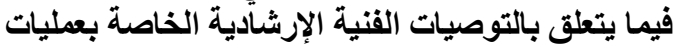

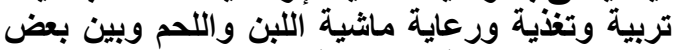
المتغيرات المستقلة المدروسة ماتية

لتحديد العلاقة بين المستوى المعرفي للمربين المبحوثين فيما يتعلق بالتوصيات الفنية الإرشادية الخاصنة بعمليات نربية المبنية

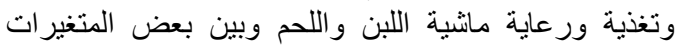

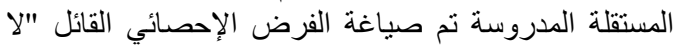

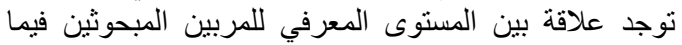

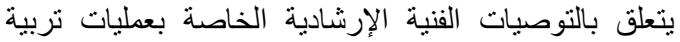

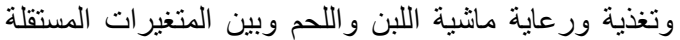

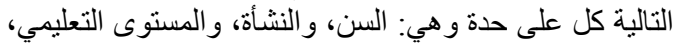

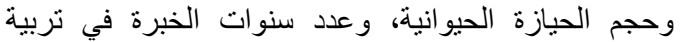

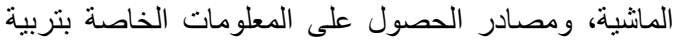

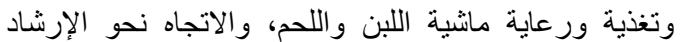

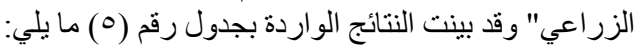
ا- السن: تبين عدم وجود علاقة معنوية بين المستوى ولئ

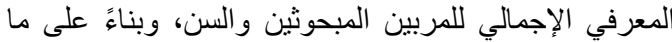

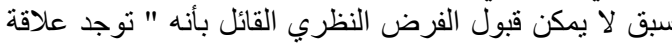

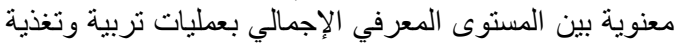

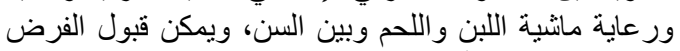

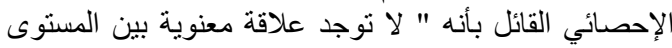
المعرفي الإجمالي للمربين المبحوثين وبين السن. r- النشأة: تبين عدم وجود علاقة معنوية بين المستوى الإنى

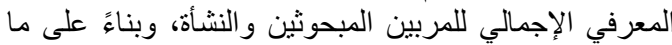

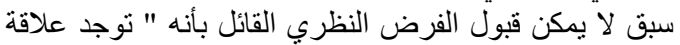

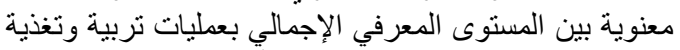

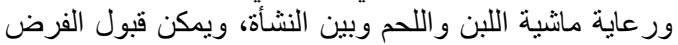

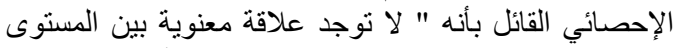
المعرفي الإجمالي للمربين المبحوثين وبين النشأنة r- المستوى التعليمي: تبين وجود علاقة معنوية بين المستوى

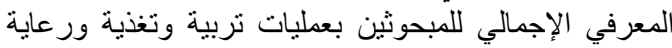


Murad et al. / Archives of Agricultural Sciences Journal 3(1) 24-35, 2020.

جدول (0): العلاقات الارتباطية بين المتغيرات المستقلة المدروسة للمبحوثين وبين المستوى المعرفي الإجمالي بعليات تربية وتغذية ور عاية مانشية اللبن و اللحم.

\begin{tabular}{|c|c|c|c|}
\hline إجمالي المعرفة & & & 5 \\
\hline$r, \cdot \varepsilon$ & قيمة كا" & \multirow{4}{*}{ 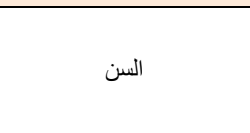 } & \multirow{4}{*}{1} \\
\hline$\cdot, 0$ & مستوى المعنوية & & \\
\hline$\varepsilon$ & درجات الحرية & & \\
\hline$\cdot, \cdot 9$ & معامل التو افق & & \\
\hline$* 1 \cdot, 97$ & قيمة كا' & \multirow{4}{*}{ عدد سنو ات الخبرة } & \multirow{4}{*}{ r } \\
\hline$\cdot, \cdot 0$ & مستوى المعنوية & & \\
\hline$\varepsilon$ & درجات الحرية & & \\
\hline$\cdot, \mathrm{IV}$ & معامل التو افق & & \\
\hline$r, T r$ & ققيمة كا' & \multirow{4}{*}{ 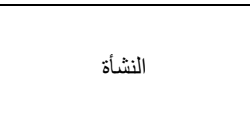 } & \multirow{4}{*}{ r } \\
\hline$\cdot, 19$ & مستوى المعنوية & & \\
\hline$r$ & درجات الحرية & & \\
\hline$\cdot, 9 \varepsilon$ & معامل التو افق & & \\
\hline$* * \wedge \varepsilon, \cdot 9$ & 'قيمة كا' & \multirow{4}{*}{ المستوى التعليمي } & \multirow{4}{*}{$\varepsilon$} \\
\hline$\because+1$ & مستوى المعنوية & & \\
\hline $1 \varepsilon$ & درجات الحرية & & \\
\hline$\cdot, \leqslant \Psi \cdot$ & معامل التو افق & & \\
\hline$* * 00, Y T$ & 'قيمة كا' & \multirow{4}{*}{ مصادر المعلومات } & \multirow{4}{*}{ 。 } \\
\hline$\cdot, \cdot 1$ & مستوى المعنوية & & \\
\hline$\varepsilon$ & درجات الحرية & & \\
\hline$\cdot$, rฯ. & معامل التو افق & & \\
\hline$* * \mid V, I V$ & قامة كا' & \multirow{4}{*}{ الاتجاه نحو الإرشاد الزراعي } & \multirow{4}{*}{7} \\
\hline$\cdot, \cdot 1$ & مستوى المعنوية & & \\
\hline$\varepsilon$ & درجات الحرية & & \\
\hline$\cdot, r \backslash 1$ & معامل التو افق & & \\
\hline
\end{tabular}

جدول (T): نوزيع المربين المبحوثين وفقاً للمشكلات التي تو اجهمح في تربية وتغذية ور عاية مانشية اللبن و اللحم (ن= • (TV).

\begin{tabular}{|c|c|c|c|c|c|}
\hline \multicolumn{2}{|c|}{$\bar{y}$} & \multicolumn{2}{|c|}{ نعم } & \multirow{2}{*}{ المشكلات } & \multirow{3}{*}{ s } \\
\hline$\%$ & عدد ( عد & $\%$ & عدد ( عد & & \\
\hline $1 \cdots$ & rv. & $1 \ldots$ & $r v$. & إجمالي المبحوثين & \\
\hline$\cdot, r$ & 1 & $99, \mathrm{~V}$ & r99 & ارتفاع سعر الأعلاف و عدم دعمها حكومياً. & 1 \\
\hline$\cdot, \wedge$ & $r$ & $99, \mathrm{r}$ & rTV & انتشار الأمر اض المعدية مثل الحمى القلاعية. & r \\
\hline$r, Y$ & $\Lambda$ & $9 \vee, \wedge$ & r4t & ضعف الخدمات الإرشادية الدقدمة. & $r$ \\
\hline Y, & $\Lambda$ & $9 \mathrm{QV}, \wedge$ & TIY & عدم وجود وحدات بيطرية قريبة منهم. & $\varepsilon$ \\
\hline$r, \xi$ & 9 & $9 \vee, 7$ & r4) & قلة عدد الأطباء البيطريين الدربين. & $\circ$ \\
\hline$r, \cdot$ & 11 & qV, $\cdot$ & roq & عدم تو افر الأدوية البيطرية وارتفاع أسعار ها. & 7 \\
\hline$r, r$ & Tr & $97, \wedge$ & ron & ضعف الخدمات البيطرية المقدمة . . & $\mathrm{V}$ \\
\hline$\varepsilon, r$ & 17 & $90, \mathrm{~V}$ & Tos & عدم وجود تأمين علي الماشية. & $\wedge$ \\
\hline 7,4 & rT & $94, \wedge$ & $r \leqslant v$ & عدم معرفة كمية العلف المثلي لتغذية ماثشية اللحم و اللبن. & 9 \\
\hline $96 \mathrm{~V}$ & ru & $9 \cdot, r$ & Trद & عدم وجود ندوات إرشادية لزيادة معارف ومهار ات مربي ماثشية اللحم و اللبن. & $1 \cdot$ \\
\hline $1 \cdot, r$ & re & $\wedge 9, y$ & ret & صعوبة إجر اءات أخذ القروض علي المانشية. & 11 \\
\hline $1 \cdot, 0$ & rq & 19,0 & Tו & ارتفاع سعر فائدة القروض. & TY \\
\hline $1 \cdot, 0$ & rq & 19,0 & Tा & عدم وجود بدائل للتغذية. & $1 T$ \\
\hline Tr, & $\varepsilon 7$ & $\Lambda \vee, \top$ & TYE & تذبذب أسعار البيع و الثر اء للحيو انات. & $1 \varepsilon$ \\
\hline 10,1 & 07 & $\Lambda \varepsilon, 9$ & TI乏 & عدم تو افر نشرات إرشادية خاصة بر عاية وتغذية المانشية. & 10 \\
\hline 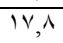 & 77 & Nr,,$T$ & $r \cdot \varepsilon$ & عدم وجود جمعيات للمربين. ع ع & 17 \\
\hline 19,0 & VY & $\lambda \cdot, 0$ & rqA & عدم تو افر المر اعي الخضر اء صيفاً. & IV \\
\hline$r r, v$ & $|r|$ & $T V, r$ & $r \leq 9$ & ضعف الخدمات التسويقية. & 11 \\
\hline$r v, \cdot$ & $1 \% \mathrm{~V}$ & $\pi$, & Trt & عدم وجود مر اكز لتجميع الألبان. & IV \\
\hline
\end{tabular}




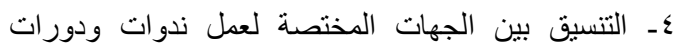

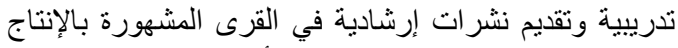

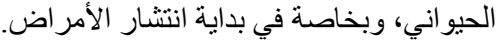

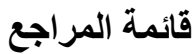

الجهاز المركزي للتعبئة العامة والإحصاء (9 ( • ب)، الكتاب الإحصائي السنوي، مايو.

السيسي، سامي محمد محمد، و غادة مصطفي عبد الفتاح

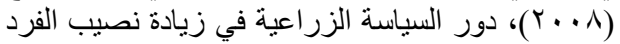

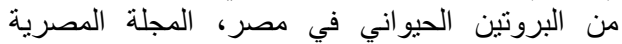
للاقتصاد الزر اعي، المجلد (1/ (1)، عدد (ع).

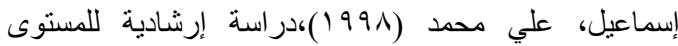

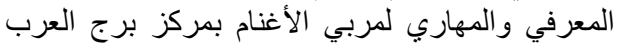

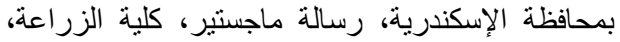
جامعة إسكندرية، جمهورية مصر العربية.

المجلة الزراعية (1 ( . ب)، مؤسسة دار التعاون للطبع و النشر ،

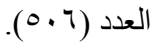

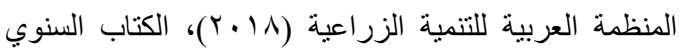

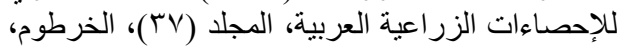

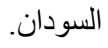

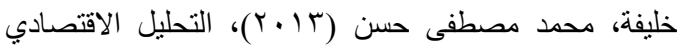

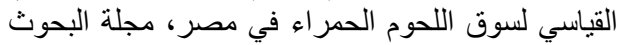

الزراعية، جامعة كفر الثيخ، مجلد (9 ب)، عدد (1) (1).

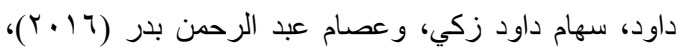

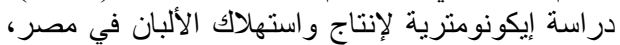

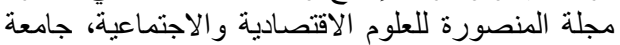

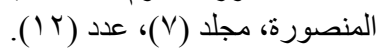

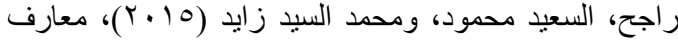

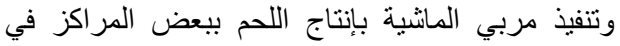
البحيرة، مجلة الإسكندرية للتبادل العلمي، مجلد (باتب)،

$$
\text { عدد (l). (1) (1) }
$$

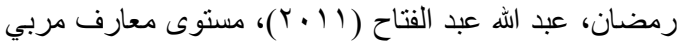

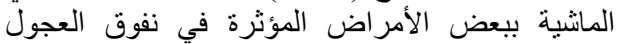
و العجلات أثناء فترة الرضاعة الأنة، مجلة الإسكندرية للتبادل

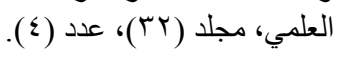

رابعا: أهم المشكلات التي تواجه المربين المبحوثين في وبي وتئي

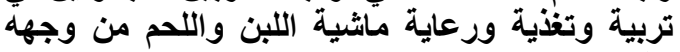
نظرهم

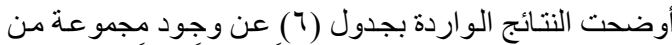

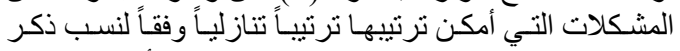

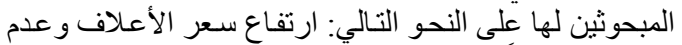

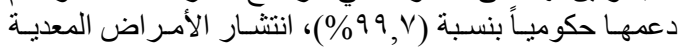

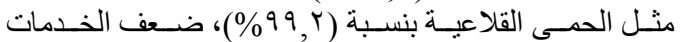

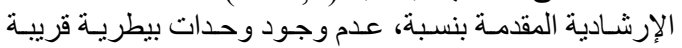

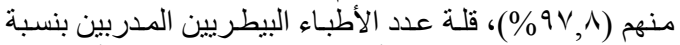

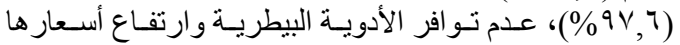

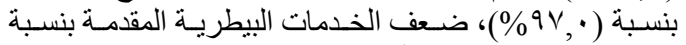

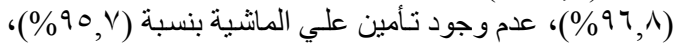

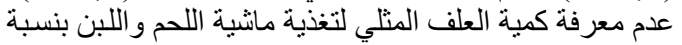

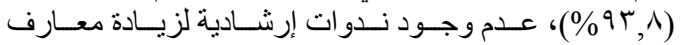

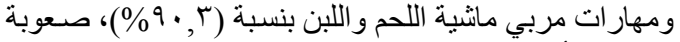

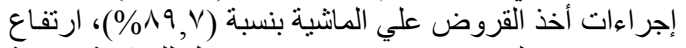

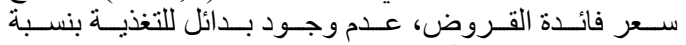

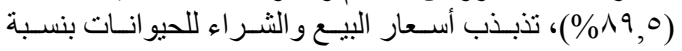

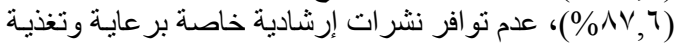

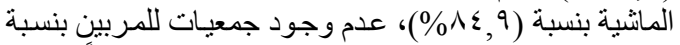

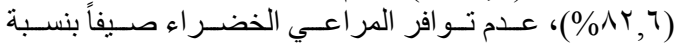

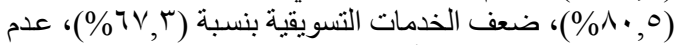

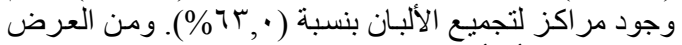

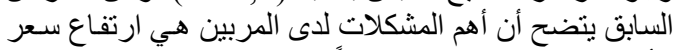

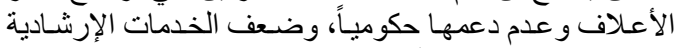

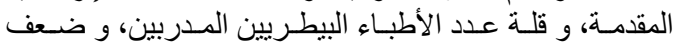

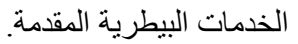

التوصيات

في ضوء النتائج التي تمخض عنها البحث يمكن الخروج

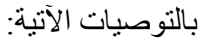

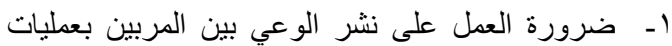

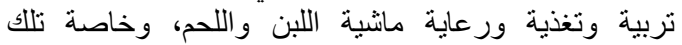

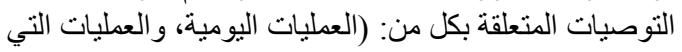

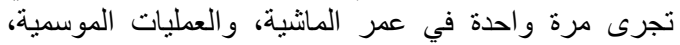
عمليات الرعاية الصحية وعلاج الأمر اض، و العمليات المتعلقة

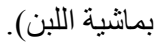

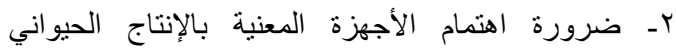

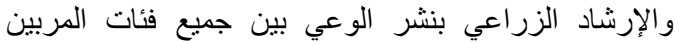
وخاصة كبار السن، و التركيز على كبار المربين الحائزين.

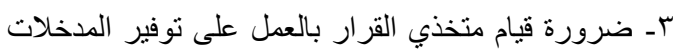

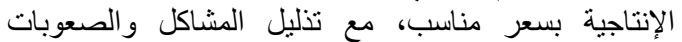
المتعلقة بعمليات تربية وتغذية ور عاية الماشية. 
Murad et al. / Archives of Agricultural Sciences Journal 3(1) 24-35, 2020.

عفيفي، أحمد عبد الله (با • ب)، حليب الماثية وإنتاج اللبن

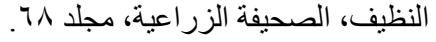

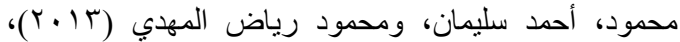

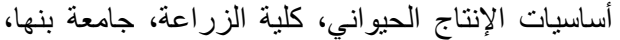
جمهورية مصر العربية.

مصر في أرقام (Y (Y.Y)، مطبعة الجهاز المركزي للتعبئة العامة والإحصاء، جمهورية مصر العرة العربية. 